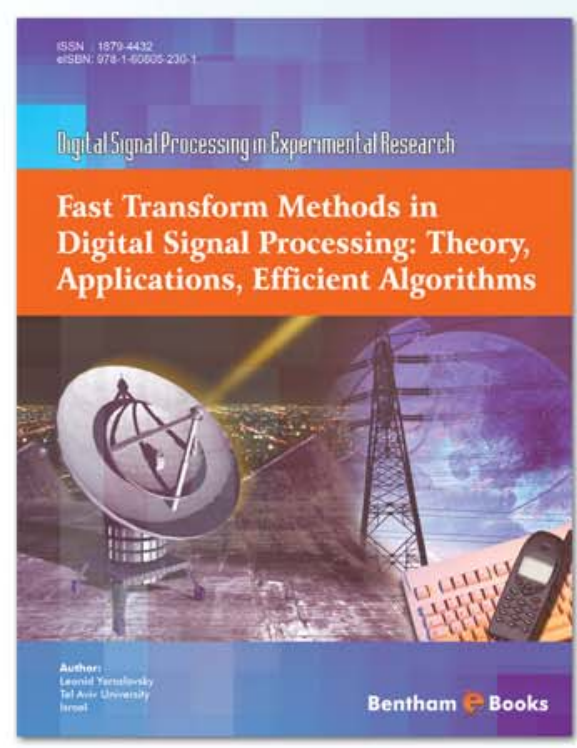

Editor/Volume Author:

\title{
Leonid Yaroslavsky
}

Israel

\section{Digital Signal Processing in Experimental Research Fast Transform Methods in Digital Signal Processing: Theory, Applications,Efficieient Algorithms}

\section{Wuwhenthamseience.com/ehooks/9781608052301}

\section{About the ebook}

This ebook covers fast transform algorithms, analyses, and applications in a single volume. It is the result of the collaboration by the author with others in the world wide university community and has been accumulated over the author's working lifetime of about 40 years. It has now culminated in a nice mix of theoretical development and practical uses of various fast transforms. Thus readers will find practical approaches not covered elsewhere for the design and development of fast transform methods.

\section{Contents}

Signal Linear Transforms: Mathematical Preliminaries

Discrete Fourier Transform and its Derivatives

Hadamard, Walsh, Wavelet and Other Transforms

- Energy Compaction Capability of Transforms

- PART 2: APPLICATIONS AND ALGORITHMS

- Signal Spectral Analysis

- Signal Restoration by Means of Linear Filtering

For Sales and Advertising Inquiries: Contact: marketing@benthamscience.org 